\title{
Knowledge and Attitudes towards Critical Thinking among Saudi International Students in the UK Universities
}

\author{
Wesal Maash ${ }^{1}$, Sarah Al-Rashdi ${ }^{2}$ \\ ${ }^{1}$ University of Exeter, ${ }^{2}$ University of Reading \\ United Kingdom
}

\begin{abstract}
The purpose of this small-scale study is to investigate Saudi students' knowledge of Critical Thinking (CT) and their attitudes towards it. The sample consisted of 121 Saudi students from 23 cities who are currently studying in UK universities with a mix of background variables (age, gender and university level). A questionnaire was developed by the researchers to be used as the tool of the study. Its validity and reliability were established. The results revealed a negative correlation between the knowledge of CT and attitudes to it. It was also indicated that statistically significant differences exist between the means of knowledge, according to university level, in favour of postgraduates. Moreover, no significant differences in the level of attitudes to CT were found according to age. Similarly, no significant differences in the knowledge of CT were found according to gender. Furthermore, the study indicated that attitudes to CT among Saudi students could be predicted based upon their university level. The study findings have contributed to the knowledge of the impact of background factors on knowledge of and attitudes to CT. As there is a debate in the literature regarding gender and university level effect on factors on knowledge of and attitudes to $C T$, the findings of this study confirms that the impact of background factors such as gender and university level differs based upon different contexts. Hence, this study suggests conducting further interpretive or mixed methods research with Saudi international students in order to understand the context in more depth.
\end{abstract}

\section{Introduction}

In recent years, CT has become a key skill for success at university, especially in the UK. According to [5], CT is one of the main demands for success in academic study in British universities. CT refers to the ability to take responsibility and develop analysing standards for a person's own thinking [1]. Gagne [2] defines CT as the capability to analyse and judge the collected evidence and information to interpret them in solving problems [2]. Similarly, [3] stresses that CT is aimed at successfully understanding, evaluating and solving problems. According to [4], CT requires a high level of thinking, which includes the process of analysis, evaluation, reasonableness and reflection. Previous research has claimed that international students in the UK lack CT, which appears in their writing [6], [7] as students from non-western countries do not have the same encouragement to practice CT. Turner [8] and Tanaka [9] have suggested that international students are frequently criticised as being noncritical thinkers due to the lack of CT practice in their approach to learning. Shaheen [5] carried out a study aimed to understand the difficulties and challenges that face international students in UK universities in order to facilitate their academic experience in UK universities. Shaheen [5] concluded that students from diverse traditions, cultures and languages approach CT tasks very differently, and this influences their academic performance negatively. Another study conducted on international students who study at one of the UK's universities indicated that there is a persistent need to re-evaluate and re-consider the way of understanding and encouraging CT in academic institutions [10].

\section{Literature Review}

The literature review shows that there has been tremendous debate about the background factors (e.g., gender, age, nationality and university level) influencing individuals' ability to think critically, their knowledge of CT and their attitudes towards it. Additionally, some studies have focused on the relationship between the ability in, the knowledge of and the attitudes to CT. Regarding CT skills, [11] found that males have higher CT skills compared to females. Furthermore, social science students perform better in CT skills compared to science and engineering students. Reference [12] argues that gender and field of study influence CT skills. It revealed that males are better critical thinkers than females and that engineering students have higher CT skills than students in the humanities and basic sciences. Regarding the knowledge of CT, [13] aimed to investigate the university students' knowledge of CT and CT skills, taking into account gender and nationality. The results revealed that Jordanian students have a greater knowledge of CT than Saudi students and that females had more knowledge of CT compared to males. In a similar manner, [14] conducted a study intended to investigate the degree of Kuwaiti intermediate teachers' knowledge and practice of CT. The study 
found that knowledge of $\mathrm{CT}$ differs according to gender, experience and major, in favour of males, longer experience and a major in social studies. Another study [15] aimed to examine both knowledge of and attitudes towards CT. It argued that there was a moderate relationship between participants' knowledge of CT and their attitudes towards it. Regarding the attitudes to CT, the same study stated that there is a difference in the participants' attitudes to CT according to the academic level (educational, non-educational) in favour of the educators and also to the years of teaching experience to the longer experience. Asgharheidari and Tahriri [22] investigated teachers' attitudes to $\mathrm{CT}$ instructions. The results indicated that teachers had a clear idea of the concept of CT and also had positive attitudes towards it. A study [16], which surveyed Hong Kong secondary school teachers, found that the participants' knowledge of CT was narrow. However, their attitudes to CT were favourable, and they expressed strong support for including it in the curriculum.

The current study focuses on Saudi international students who are studying in UK universities. The reason for choosing this particular context is that Saudi Arabia has just started to include a curriculum for CT in schools in the past year [17], which means that many Saudi graduates might not have practised or had knowledge of CT until they started studying in the UK. According to Higher Education Statistics Agency (HESA) website, Saudi students represent one of the majorities of the international students in UK universities [18]; thus, this is an interesting context to focus on. As there is a lack of studies conducted on international students' knowledge of and attitudes to $\mathrm{CT}$, and for the importance of investigating a specific context such as Saudi international students, this study intended to draw a picture of what the reality is and then suggest solutions. It also appears from the previous literature that the impact of background factors differs based on different contexts [13-16]. Therefore, this study was particularly interested in examining gender and university level, as there has been some debate on the impact of these factors on knowledge of and attitudes towards CT among Saudi students in UK universities. This study will also look at the factor of age as it has not been studied in relation to CT.

\section{Methodology}

The current study is underpinned by the postpositivism paradigm. Hence, the methodology used is purely quantitative [24]. In the following, the research design is specified, followed by an explanation and justification of the sampling technique with a detailed description of the study participants.

\subsection{Research Design}

The current study aims to investigate Saudi international students' awareness of CT in relation to their attitudes to it in a group of mixed age, mixed genders and mixed university levels in the UK. The study focuses specifically on three key points:

i. The relationship between Saudi students' knowledge of CT and their attitudes to it.

ii. The impact of the background variables of age and gender on Saudi students' knowledge of CT and their attitudes to it.

iii. The possibility of predicting Saudi students' levels of knowledge of CT is based upon a combination of these variables: attitudes to $\mathrm{CT}$, age and university level.

For the purpose of this study, a survey design has been used to collect quantitative data in order to identify the variables it is intended to measure [19, 20]. Data are collected by asking the participants questions via an online questionnaire [20]. We built two scales: one for the knowledge of CT and the other for the attitudes to CT. Both scales were combined in one online survey, which also collected the participants' background information.

\subsection{Participants and Sampling}

The overall number of Saudi students in UK universities in 2019 (when the study was conducted) was 6,490 [18]. As the details of this population background, such as gender, age and university levels, are unknown, and because of the time and budget limitations of this small-scale enquiry, the most appropriate technique was convenience sampling, where respondents would be selected because of their convenient accessibility to the researchers [21]. Although this approach to sampling means that the results of this study cannot be generalised, it can serve future studies in the field as an example that gives an idea of Saudi students' CT attitudes and knowledge.

Accordingly, we sent an instruction sheet with the questionnaire link by email to the gatekeepers (Saudi students' official club leaders) in 38 cities in the UK. The gatekeepers from 23 cities responded and agreed to pass on the questionnaire link to their members (Saudi students). The final sample consisted of 121 participants: $51 \%$ female and $49 \%$ male. Of these participants, $8 \%$ were aged 20 years or under, $7 \%$ were aged $21-25$ years, $37 \%$ were aged $26-30$ years, $37 \%$ were aged $31-35$ years, and $17 \%$ 
were aged 36 years or over. In total, $10 \%$ were undergraduate students, while $90 \%$ were postgraduate students.

\section{Analysis of Findings and Discussion}

The Statistical Package for the Social Science (SPSS) was used to run statistical analysis of the collected data. A number of tests (descriptive and inferential) were then run. To test the normality of the collected data, the Kolmogorov-Smirnov test of normality was administered. Due to the sample size being above 50 participants $(n=121)$, the Kolmogorov-Smirnov Test was deemed more appropriate as it provides a more powerful test of normality [26]. To test the study hypotheses, several statistical tests were administered: Mann-Whitney, Kruskal-Wallis, Spearman's correlation and Multiple Regression Linear. In the following, a discussion of each finding is presented.

\subsection{Relationship between Knowledge of and Attitudes to CT}

The study revealed that the correlation between knowledge and attitudes is considered low (see Table 1). As the rho value is between 0.10 and 0.29 [24], there is a small negative correlation between the two variables ( $r h o=-0.26, n=121, p<0.003$ ) with a high level of attitude to CT associated with a lower level of knowledge of CT.

Table 1 shows interesting findings. The negative correlation between knowledge of CT and attitudes towards it suggests that students who presented a narrow understanding of CT tended to have high attitudes to CT. This is not surprising, as [16] indicated similar results. Whilst most of the teachers in that study did not have a clear idea about the meaning of CT, they believed that teaching CT skills were essential and that they should be trained to

Table 1. Correlations

\begin{tabular}{|c|c|c|c|c|}
\hline & & & Total Knowledge & Total Attitude \\
\hline \multirow[t]{6}{*}{ Spearman's rho } & Total & Correlation Coefficient & 1.000 & $-0.264 * *$ \\
\hline & Knowledge & Sig. (2-tailed) & . & 0.003 \\
\hline & & $\mathrm{N}$ & 121 & 121 \\
\hline & Total & Correlation Coefficient & $-0.264 * *$ & 1.000 \\
\hline & Attitude & Sig. (2-tailed) & 0.003 & . \\
\hline & & $\mathrm{N}$ & 121 & 121 \\
\hline
\end{tabular}

teach it to their students. However, other studies (e.g. [22], [15]) have shown a positive relationship between knowledge of and attitudes towards CT. This is perhaps because the participants in these studies had high awareness and understanding of CT. In other words, both high and low levels of knowledge of CT perhaps motivate individual attitudes to CT.

\subsection{Effect of Degree Level on Knowledge of CT}

The study revealed a statistically significant difference in the knowledge levels across two university levels (undergraduates, $\mathrm{Md}=6.5, \mathrm{n}=12$ and postgraduates, $\mathrm{Md}=9, \mathrm{n}=109$ ). In Tables 2 and $3, \mathrm{U}=348, \mathrm{z}=-2.68, \mathrm{p}=0.007$, which indicates that postgraduates have a higher level of knowledge of CT compared to undergraduates.

Table 2. Test for Knowledge and University Level

\begin{tabular}{cc}
\hline \hline & Total Knowledge \\
\hline Mann-Whitney U & 348.000 \\
Wilcoxon W & 426.000 \\
Z & -2.684 \\
Asymp. Sig. (2-tailed) & 0.007 \\
\hline \multicolumn{2}{c}{ a. Grouping Variable: University level }
\end{tabular}


Table 3. Median Scores for Each University Level

\begin{tabular}{ccc}
\hline \hline & Total Knowledge & \\
\hline University level & Median & $\mathrm{N}$ \\
\hline Undergraduate & 6.5 & 12 \\
Postgraduate & 9.0 & 109 \\
Total & 9.0 & 121 \\
\hline \hline
\end{tabular}

It appears from this result that the university level had a great impact on knowledge of CT. This result suggests that postgraduates have greater knowledge of CT compared to undergraduates. It could be speculated that the reason for the postgraduates scoring higher on the knowledge test is because the postgraduate programmes in the UK usually include more complicated tasks that require a higher level of CT compared to undergraduate programmes. It could also be argued that the acceptance criteria of undergraduate programmes demand a moderate language score that students can easily achieve without taking pre-sessional courses, whereas postgraduate programmes require a higher level of language, so students usually undertake pre-sessional courses which are focused on CT. Therefore, this could be the reason why they have a better knowledge of CT.

\subsection{The Effect of Age on Attitudes to CT}

The study revealed that there are no statistically significant differences (Chi-square $=6.02, \mathrm{p}=0.20$, $\mathrm{df}=4$ ) found in attitudes to CT between the five age groups (see Tables 4 and 5). This means that Saudi students of different ages do not have statistically significant different attitudes to $\mathrm{CT}$.

Table 4. Test for Attitudes and Age

\begin{tabular}{cc}
\hline \hline & Total Attitude \\
\hline Kruskal-Wallis H & 6.015 \\
df & 4 \\
Asymp. Sig. & 0.198 \\
\hline \hline \multicolumn{2}{c}{ a. Kruskal Wallis Test } \\
b. Grouping Variable: Age
\end{tabular}

Table 5. Median Scores for Each Age

\begin{tabular}{cccccc}
\hline \hline & & Total Attitude & & \\
\hline Age & $\mathrm{N}$ & Median & Sum & Mean & Std. Deviation \\
\hline 20 years or under & 1 & 63.00 & 63 & 44.00 & 1.263 \\
21-25 years & 9 & 42.00 & 404 & 43.40 & 11.986 \\
26-30 years & 45 & 40.00 & 1953 & 41.78 & 12.413 \\
31-35 years & 45 & 42.00 & 1880 & 39.76 & 16.214 \\
36 years or over & 21 & 35.00 & 835 & 42.44 & 12.930 \\
Total & 121 & 40.00 & 5135 & & \\
\hline \hline
\end{tabular}

In this study, the assumption of a relation between attitudes to $\mathrm{CT}$ and age was made based on the idea that age is considered a life experience, and the previous studies in the literature [14] attributed having a higher level of attitudes to CT to longer teaching experience. Nonetheless, it seems that life experience does not have the same impact as teaching experience.

\subsection{The Effect of Gender on Knowledge of CT}

The study revealed no significant difference in the knowledge levels of males $(\mathrm{Md}=9.0, \mathrm{n}=62)$ and females $(\mathrm{Md}=9.0, \mathrm{n}=59), \mathrm{U}=1737, \mathrm{z}=-0.49, \mathrm{p}=$ $0.94, r=0.04$ (Tables 6 and 7). This indicates that there is no statistically significant difference between the knowledge of CT among female and male Saudi students. This is an interesting finding in contrast with the findings of [13], which was also conducted with Saudi students and revealed that females had a greater knowledge of CT. The difference between the current study and [13] is the setting, as that study was conducted with local students who study in Saudi Arabian universities; based on segregated genders, there might be some dissimilarities in the way in which the two genders are taught CT. While this study was conducted with Saudi students who study in the UK universities in mixed classes, both genders should have received the same instruction regarding CT. As a result, no differences regarding knowledge of CT were found. 
Table 6. Test for Knowledge and Gender

\begin{tabular}{cc}
\hline \hline & Total Knowledge \\
\hline Mann-Whitney U & 1736.500 \\
Wilcoxon W & 3506.500 \\
Z & -0.485 \\
Asymp. Sig. (2-tailed) & 0.628 \\
\hline \hline a. Grouping Variable: Gender
\end{tabular}

Table 7. Median Scores for Each Gender

\begin{tabular}{ccc}
\hline \hline & Total Knowledge \\
\hline Gender & Median & $\mathrm{N}$ \\
\hline Male & 9.0 & 62 \\
Female & 9.0 & 59 \\
Total & 9.0 & 121 \\
\hline \hline
\end{tabular}

\subsection{The Predictability of Attitudes towards CT}

To indicate whether the attitude to $\mathrm{CT}$ is predictable based on level of knowledge of $\mathrm{CT}$, age, university level or gender, a Multiple Linear Regression Test was performed to analyse the predictive model. With the adjusted $r$ square value of 0.049 , the model predicted a $5 \%$ assumption of the variance in the dependent variable (see Table 8 ). The multiple regression model in Table 1 showed significant positive regression, $\mathrm{f}(4,12)=2.54$, $\mathrm{p}<$ 0.04 (see Table 9), indicating that at least one or more of the test's predictors had a statistically significant association with students' attitudes to CT.
The models suggested that students' university level had a significant effect on their attitudes to CT; as university-level tended to rise, their attitudes to CT tended to rise significantly $(\mathrm{B}=-9.3, \mathrm{p}=0.03<$ 0.05). However, the student's gender, age and knowledge of CT were not statistically significantly associated with the students' attitudes to CT, as shown by their $p$ values which exceeded the alpha significance level of 0.05 (see Table 10). The size of the multipliers is in the following regression equation: attitude to $\mathrm{CT}=-9.29$ university level +65.741 .

Table 7. The Predictive Model

\begin{tabular}{ccccc}
\hline \hline Model & $\mathrm{R}$ & R Square & Adjusted R Square & Std. Error of the Estimate \\
\hline 1 & $0.248^{\mathrm{a}}$ & 0.080 & 0.49 & 12.611 \\
\hline \hline & a. Predictor: & $\begin{array}{c}\text { (Constant), University level, Gender, Total Knowledge, Age } \\
\text { b. Dependent Variable: Total Attitude }\end{array}$
\end{tabular}

Table 9. ANOVA

\begin{tabular}{ccccccc}
\hline \hline & Model & Sum of Squares & df & Mean Square & F & Sig. \\
\cline { 2 - 6 } 1 & Regression & 1612.852 & 4 & 403.213 & 2.535 & $0.044^{\mathrm{b}}$ \\
Residual & 18448.933 & 116 & 159.043 & & \\
Total & 20061.785 & 120 & & \\
\multicolumn{6}{c}{ a. Dependent Variable: Total Attitude } \\
\multicolumn{6}{c}{ b. Predictors: (Constant), University level, Gender, Total Knowledge, Age }
\end{tabular}


Table 10. Coefficients

\begin{tabular}{|c|c|c|c|c|c|c|}
\hline & \multirow[t]{2}{*}{ Model } & \multicolumn{2}{|c|}{$\begin{array}{c}\text { Unstandardized } \\
\text { Coefficients } \\
\end{array}$} & \multirow{2}{*}{$\begin{array}{c}\text { Standardized } \\
\text { Coefficients } \\
\text { Beta }\end{array}$} & \multirow[t]{2}{*}{$\mathrm{t}$} & \multirow[t]{2}{*}{ Sig. } \\
\hline & & B & Std. Error & & & \\
\hline \multirow{5}{*}{1} & (Constant) & 65.741 & 8.400 & & \multirow{5}{*}{$\begin{array}{c}7.826-1.075 \\
.463 \\
-.672 \\
-2.211\end{array}$} & 0.000 \\
\hline & Total Knowledge & -0.430 & 0.400 & -0.098 & & 0.284 \\
\hline & Gender & 1.073 & 2.318 & 0.042 & & 0.644 \\
\hline & Age & -0.939 & 1.397 & -0.064 & & 0.503 \\
\hline & University level & -9.286 & 4.200 & -0.216 & & 0.029 \\
\hline
\end{tabular}

The above findings indicate that only the university level can predict the attitudes to CT. This result is consistent with the findings of [15], which revealed the influence of the level of education on students' attitudes to CT. This may be related to the previous discussion regarding the relationship between university level and knowledge of CT. It may also be related to the nature of postgraduate studies contributing to raising students' awareness of the importance of CT.

\section{Limitation}

The current study has the following limitations:

- Limited time - Due to the limited time of smallscale studies, the questionnaire link was open for only a week, which had a negative impact on the response rate.

- Small pilot sample - Also due to the time constraints, the questionnaire was only piloted with 12 participants. A larger piloting sample might have allowed the researchers to test and ensure the reliability of the scales before conducting it on the study sample.

- The convenience sampling - The sample size was appropriate to collect meaningful data. However, the use of the convenience sampling technique made the generalisation of the findings impossible [25].

- The non-normal distribution - The data were not normally distributed, which results in using less powerful (non-parametric) tests.

\section{Conclusion}

The aim of this small-scale study was to determine the relationship between Saudi international students' knowledge and their attitudes to CT and the impact of background variables: age, gender and university level. The study used a questionnaire with two scales to gather the data. The study had several results: (1) Saudi students' knowledge of CT correlated negatively with their attitudes to $\mathrm{CT}$, (2) knowledge of $\mathrm{CT}$ differs according to university level, in favour of postgraduates, (3) there is no difference according to the age in the level of attitudes to CT, (4) there is no difference in the level of knowledge of CT between males and females, and (5) Saudi students' attitudes to $\mathrm{CT}$ can be predicted based upon their university level. These results are important for education and curriculum development research in order to pay more attention to teaching and learning CT. This study recommends conducting further investigations on the impact of specialisms on international students' knowledge of and attitudes to CT. Furthermore, it suggests that conducting further interpretive or mixed methods research with Saudi international students might help to understand the context in more depth.

\section{References}

[1] Elder L, Paul R. Critical thinking: Why we must transform our teaching. Journal of Developmental Education. 1994;18(1):34-5.

[2] Gagne RM. Some reflections on thinking skills. Instructional Science. 1988;17(4):387-90.

[3] Maiorana VP. Critical thinking across the curriculum : building the analytical classroom. Bloomington, Ind.: Eric Clearinghouse on Reading And Communication Skills; 1992.

[4] Jeevanantham LS. Why teach critical thinking? Africa Education Review. 2005 Jan;2(1):118-29.

[5] Shaheen N. International students' critical thinkingrelated problem areas: UK university teachers' perspectives. Journal of Research in International Education. 2016 Mar 31;15(1):18-31.

[6] Huang R. CT: discussion from Chinese postgraduate international students and their lecturers. Journal of Hospitality, Leisure, Sport and Tourism Education. 2008;4(23):1-12.

[7] Kim H-K. Critical Thinking, Learning and Confucius: A Positive Assessment. Journal of Philosophy of Education [Internet]. 2003 Feb [cited 2019 Dec 13];37(1):71-87. http://onlinelibrary.wiley.com/doi/10.1 
111/1467-9752.3701005/abstract. (Access Date: 3 January 2022).

[8] Turner Y. Students from mainland China and critical thinking in postgraduate Business and Management degrees: teasing out tensions of culture, style and substance. The International Journal of Management Education. 2006 May 1;5(1):3-11.

[9] Tanaka J. Academic difficulties among East Asian international graduates: Influences of perceived English language proficiency and native educational/socio-cultural background [Doctoral dissertation]. [Indiana University Bloomington]; 2002.

[10] Hammersley-Fletcher L, Hanley C. The use of critical thinking in higher education in relation to the international student: Shifting policy and practice. British Educational Research Journal. 2016 Sep 12;42(6):978-92.

[11] Rodzalan SA, Saat MM. The Perception of Critical Thinking and Problem-Solving Skill among Malaysian Undergraduate Students. Procedia - Social and Behavioural Sciences. 2015 Jan;172(2015):725-32.

[12] Aliakbari M, Sadeghdaghighi A. Investigation of the relationship between gender, field of study, and critical thinking skill: the case of Iranian students. In: The 16th Conference of Pan-Pcific Association of Applied Linguistics, The Chinese University of Hong Kong. 2011. p. $301-10$.

[13] Abu-Tayeh S. The Knowledge of Class-teacher University Students of Creative Thinking and Critical Thinking Skills considering Some Variables [Translated from Arabic]. Scienes and Arts - Studies and Research. 2009;21(1).

[14] Al-Sinafi S. Kuwait Intermediate Social Studies Teaches' Knowledge and Performance of the Critical Thinking Skills as Received by Themselves [Translated from Arabic]. Dirasat Educational Sciences. 2004;35:68496.

[15] Al-Sulaiman S. The extent of knowledge of critical thinking and attitude towards it among social science teachers in the middle school in Saudi Arabia [Translated from Arabic]. Egyptian Association for Curricula and Teaching. 2001;(74):115-45.

[16] Stapleton P. A survey of attitudes towards critical thinking among Hong Kong secondary school teachers: Implications for policy change. Thinking Skills and Creativity. 2011 Apr;6(1):14-23.

[17] Makhlouf, A. M. Saudi Schools' Openness to Change in Light of the 2030 Vision. American Journal of Educational Research. 2021 Feb 1;9(1):52-60.

[18] HESA. Higher education Statistics Agency [Internet]. www.hesa.ac.uk. [cited 2021 Jul 1]. Available from: https://www.hesa.ac.uk. (Access Date: 3 January 2022).

[19] Levy PS, Lemeshow S. Sampling of Populations: Methods and Applications. 4th ed. New York: John Wiley and Sons; 2011.
[20] Groves RM, Fowler FJ, Couper M, Lepkowski JM, Singer E, Tourangeau R. Survey methodology. 2nd ed. Hoboken, N.J.: Wiley; 2009.

[21] Higginbottom GMA. Sampling issues in qualitative research. Nurse Researcher. 2004 Jul;12(1):7-19.

[22] Asgharheidari F, Tahriri A. A Survey of EFL Teachers' Attitudes towards Critical Thinking Instruction. Journal of Language Teaching and Research. 2015 Mar 10;6(2):388-96.

[23] Pallant J. SPSS survival manual: A step by step guide to data analysis using SPSS for Windows [Internet]. 2007 [cited 2021 Jun 16]. Available from: http://mcgrawhill.co.uk/openup/chapters/0335208908.pdf. (Access Date: 3 January 2022).

[24] Cohen J. Statistical power analysis for the behavioural sciences. 2nd ed. Hillsdale, NJ: Lawrence Erlbaum Associates; 1988.

[25] Thomas G. How to do a research project: a guide for students in education and applied social sciences. Thousand Oakes, Calif.: Sage; 2009.

[26] Field, A. Discovering statistics using SPSS. 3rd ed.. London: SAGE; 2009. 